Published in British Journal of Social Work (2018) 48, 906-923 Accepted for publication February 2018

\title{
Understanding the risks of financial scams as part of elder abuse prevention
}

Lee-Ann Fenge* and Sally Lee

Faculty of Health and Social Science, Bournemouth University, R408 Royal London House, Bournemouth, BH1 3LT, UK *Correspondence to Professor Lee-Ann Fenge, Faculty of Health and Social Science, Bournemouth University, R408 Royal London House, Christchurch Road, Bournemouth, BH1 3LT, UK. E-mail: Ifenge@bournemouth.ac.uk

\section{Abstract}

Financial scams have been described as the crime of the $21^{\text {st }}$ century, representing a global challenge for agencies involved in the protection of older people at risk of financial abuse. Financial abuse is the second most common form of adult abuse, but traditionally research has focused on abuse which occurs within relationships of trust within families. Less is known about financial scams perpetrated by individuals or organisations unknown to the individual, and which specifically target older people. In part this is because financial scams are often underreported as victims can be reluctant to disclose their experience, posing challenges to those who have a safeguarding role.

This paper discusses factors emerging from the literature which act as triggers for scam involvement. These include loneliness, emotional vulnerability linked to life events, cognitive impairment and mental capacity. The findings of a small exploratory qualitative study with older people and their carers $(n=12)$ who have experienced financial scams will be discussed in relation to the literature. These provide unique insights into the experience of being scammed and the impact on individual health and well-being. Key themes will be discussed in relation to social work practice and integrated working across health and social care.

\section{Introduction}

Globally there is increased recognition of the risks posed by financial abuse of older people (Adult Social Care Statistics, 2016; NCA, 2015; Li, 2016; Smith and Budd, 2009), and it has been suggested that 'the financial exploitation of older people has emerged as a virtual epidemic in high-income countries' (Penhale, Lloyd-Sherlock and Lachs, 2017, p. 725). Traditionally research and policy on financial abuse has focused on abuse which occurs 
within families or care settings (SCIE; 2011, Gibson and Qualls, 2012; Redmond, 2016). However, there is growing international recognition of the threat posed by financial scams and mass marketing fraud perpetrated by those unknown to the victim and specifically targeted at older people (Carach et al. 2001; NCA, 2015; Li, 2016), and the need to support older people to better protect themselves from scams linked to identity crime (Cross, 2017). This paper uses the term financial scam to denote financial abuse perpetrated by those unknown to the victim linked to 'unscrupulous traders or criminals who employ marketing techniques to sell non-existent, valueless or poor quality goods, or engage consumers in bogus schemes such as investment fraud' (Lee and Baxter, 2017, p. 24).

Financial scams are not a new phenomenon, but changing methods of mass communication have supported a proliferation of mass marketing frauds and scams which target specific population groups, such as older people or those who may be lonely or socially isolated (National Trading Standards Scams Team, 2015). Scams take different forms perpetrated via the door step, mail, telephone and internet. Different approaches may target different population groups, and a US study found that the telephone was the most commonly used method of contact for older people targeted for consumer fraud (Holtfreter, Reisig, Mears, \& Wolfe, 2014). However, other research suggests that there is no typical victim profile (Holtfreter et al. 2006).

Currently there is little research into the perpetrators of financial scams (Button et al., 2009), although all share a financial motivation for their crime. As scams appear in many guises, it is likely that perpetrators will have different backgrounds. For example, in terms of door step scams, it is known that perpetrators may travel widely to commit scams, including across national and international borders (Barratt, 2012; Europol, 2011). It is also reported that doorstep scammers often search for visible indicators of vulnerability at houses such as ramps or key safe boxes (Day, 2017). Those perpetrating mail, telephone and cyber scams may be more elusive as they normally have no physical contact with the victim. They are therefore difficult to identify, particularly as scams are often perpetrated across international borders. As Button et al. (2009, p.13) suggest 'even the law enforcement community does not always know the background of the perpetrators'.

The scale of the issue is difficult to measure as many victims never report their involvement, or hide their financial loss from family and friends for fear of being blamed for their involvement (Cross, 2016). It affects older people across the world and it is estimated that 1 in 18 cognitively intact older people in the US experience financial scams each year (Burnes et al. 2017); whilst in the UK, research suggests that the threat posed by financial scams 
targeted at vulnerable groups is growing (Financial Fraud Action UK, 2014). In Australia, it is suggested that financial fraud and scams represent the most common type of crime experienced by older people (Smith and Budd 2009). Due to under reporting it is difficult to get an accurate picture of the financial losses involved, although in the UK it has been estimated that scams cause between $£ 5$ to $£ 10$ billion of detriment annually (NTS Scams Team, 2015).

In England, the Care Act 2014 brings financial abuse from scamming into focus as an adult safeguarding concern for the first time. The Care Act 2014 Statutory Guidance (DH, 2016) states that financial or material abuse includes "theft, fraud, internet scamming, coercion in relation to an adult's financial affairs or arrangements" (DH, 2016, 14.17). This links scam involvement with the safeguarding responsibilities of health and social care professionals. $A$ scam, like any form of abuse, can be a one-off event or a longer-term interaction, resulting in chronic victimisation (SCIE, 2011).

This paper explores factors emerging from the international literature which may act as risk factors for scam involvement. These factors include loneliness and social isolation, emotional vulnerability linked to life events such as bereavement, cognitive impairment and mental capacity. The findings of a small exploratory qualitative study with older people and their carers $(n=12)$ who have experienced financial scams will be discussed in relation to the emergent literature. The interviews provide unique insights into the experience of being scammed and the impact on the health and well-being of victims and their families/carers. Key themes arising from this research will be discussed in relation to the implications for social work practice and integrated working across health and social care.

\section{Background literature}

Why and how individuals become involved in scams is complex involving predisposing factors which increase individual vulnerability such as cognitive impairment (Marson et al., 2009) and loneliness (Reibolt and Vogel, 2003); individual financial decision making ability (Lichtenburg et al. 2016); and 'persuasive methods' employed by scammers to entrap victims (Whitty, 2015). Due to different reporting mechanisms it is difficult to establish what the most common method of scamming is, and as Cross (2016, p.61) suggests 'given the diversity of fraud, there is no universally accepted explanation to account for fraud victimisation'. 
When considering involvement in a financial fraud or scam it is therefore important to adopt a person-centred approach which acknowledges the intersection of various factors which contribute to individual vulnerability and individual assets which may support the individual to protect themselves and prevent victimisation. This is particularly relevant for practitioners and agencies whose role it is to protect those adults who may be at risk of financial scam exploitation. The following section explores some of the key factors linked to financial scam involvement emerging from the literature.

\section{Loneliness and social isolation}

Loneliness is a subjective feeling and does not necessarily relate to having no social connections or relationships, for example an individual may feel lonely whilst living in group living settings (Theurer et al. 2015). Social isolation however describes a situation in which the individual lacks social connections or contacts. Feeling lonely or having no social contacts may increase emotional vulnerability and as a result increase susceptibility to responding to a scam (Reibolt and Vogel, 2003; Olivier et al. 2015).

Socially isolated older adults have been described as being 'highly vulnerable to financial scams and manipulations' (Lubben et al. 2015, p.5) as people who feel lonely may respond positively to any form of social contact, even when this occurs as part of a ploy to exploit them for financial gain. In the UK a recent Doorstep Crime Victim Impact Survey indicated that $57 \%$ of the people who reported doorstep scams lived alone, and $34 \%$ had experienced recent bereavement (National Trading Standards Board, 2015). Socially isolated older people are more likely to respond to telemarketing phone calls, doorstep sales, scam mail and listen to a sales pitch (Lee and Geistfeld, 1999).

This type of social and emotional vulnerability may make older people specific targets for scammers who use lures and approaches which reinforce a 'relationship' with the victim which makes them feel special (Lea and Webley, 2006). Victims can develop strong attachments to the person who is scamming them based on a 'social relationship' which is reinforced over time and through multiple contacts. Grooming an individual through the establishment of a relationship which is built over time is one way in which scammers may exploit lonely individuals, and strong relationships may develop between the victim and perpetrator as a result of the quantity rather than quality of the contact (Kang and Ridgway, 1996). 
Romance scams in particular exploit an individual's desire for a meaningful social relationship and can be emotionally devastating for the victim (Whitty and Buchanan, 2012). Such scams have been described as offering a false relationship (Budd and Anderson, 2009), and involve a scammer grooming an individual over time to make them believe that an emotional relationship exists, before the scam itself takes place (Arms, 2010). This is described by Whitty (2013) as a period of grooming intended to increase the intimacy between the victim and scammer.

Cross (2016) argues that focusing on detriment models such as loneliness and social isolation feeds into a discourse linked to vulnerability, which prevents individuals from coming forward to report the crime. However, it could be argued that approaches which acknowledge the impact of loneliness and social isolation as risk factors for scam involvement may enable agencies to offer support which builds on social connectedness. This may lead to initiatives which support individuals and communities to combat loneliness (Nicholl, 2014), and build upon a community assets approach to combating financial scams.

\section{Mental capacity and cognitive impairment}

Cognitive decline linked to dementia has been reported to have a negative impact on financial management skills (Alzheimer's Society, 2011), and cognitive impairment in couples in which one party had cognitive deficits has been linked to increased financial difficulties (Hsu and Willis 2013). Individuals with dementia may have reduced financial capacity to judge risk, and may encounter difficulties with financial decision making increasing the risk of responding to a scam (Choi et al., 1999; Marson et al., 2009). Reduced cognitive ability is predictive of higher susceptibility to scam involvement (Gamble et al. 2014), and may undermine individual financial autonomy due to reduced financial decision making ability (Marson 2001; Marson et al., 2009). Individuals may be at increased risk of financial exploitation as they have reduced ability to detect and prevent financial scams (Stiegal, 2012). However, currently there is limited research exploring financial capacity for those with dementia (Boyle, 2013), and it is important to judge individual capacity rather than relying on generalisations linked to cognitive state.

Individuals with dementia may be an attractive target for exploitation by scammers as it can be more difficult to detect scams and financial abuse in people who have dementia because of a lack of confidence in their credibility (Alzheimer's Society, 2011). Research into the impact of mild cognitive impairment suggests that reduced abilities linked to perceptual 
speed and episodic memory, may contribute to greater susceptibility to scams (Han et al. 2015). This makes the individual less able to distinguish between a genuine financial contact and a scam, and less able to make judgements linked to the value of money.

Lichtenberg (2016) urges caution in making generalisations about cognitive impairment and financial decision making ability, suggesting that each individual's right to autonomy be considered carefully in adult protection assessments. Such an approach goes hand in hand with enabling people with dementia to safeguard themselves to promote individual resilience and autonomy (Clarke, 2009). However, whilst adopting an approach which acknowledges individual capacity and autonomy it is also important that professionals remain alert to the risks posed by financial exploitation of those with dementia in whatever setting they are living and take appropriate action (Samsi et al. 2014).

\section{Psychological and emotional factors}

An individual's emotional or psychological state may influence how they respond to a scam contact or how likely they are to respond to being manipulated by scam techniques. For example, in romance scams it has been suggested that the success of the scam pivots around how it 'appeals to the strong emotions of the victim because of the powerful nature of romantic relationships and love' (Kopp, et al. 2015, p.216). Aside from specific romance scams, emotions may exert an influence on the financial decisions individuals take, and it is suggested that older people's decision making abilities may be particularly influenced by high-arousal emotions (Carstensen, Mikels, and Mather, 2006).

Scammers exploit emotional responses by designing scams which require quick decisions. In these pressurised situations scammers play on visceral influences to elicit an emotional rather than judgement based response (Lagenderfer and Shrimp, 2001; Fischer, Lea and Evans, 2013). Research exploring high emotional arousal on scam susceptibility suggests that high emotional states, linked to excitement and anger, increase older people's response to misleading advertisements (Kircanski et al. 2016). Exploratory research into neuro functions and scam susceptibility in healthy older adults suggests a link to changes in areas of the brain involved in socio-emotional, which may act as a marker for increased financial exploitation risk (Sprenge et al. 2017). In a small scale study of older scam victims Olivier et al. (2015) explore how victims felt 'played' by the scammers as their emotional needs were preyed upon, and may be particularly emotionally vulnerable as a result of specific life events such as bereavement. 
Psychological variables linked to risky decision making have been highlighted in the literature, and those concerned or uncertain about their income post retirement may respond to more high risk financial decisions (Lichtenburg, et al. 2016). However, other researchers challenge deficit models which emphasis the emotional vulnerability of older people to scams as these approaches tend to ignore the protective factors that older adults use to avoid financial exploitation (Ross, Grossmann and Schryer, 2014). This suggests that practitioners should explore individual strengths and assets which support individuals to safeguard themselves.

This brief literature review has demonstrated the complexities and competing discourse which frame understanding of older people's involvement with financial scams. The following section explores the results of a small exploratory study before discussing these in relation to emergent themes within the literature.

\section{Methodology}

This small explorative study used a qualitative narrative approach using semi-structured interviews with individuals and their carers who had experienced financial fraud $(n=12)$. The interview protocol contained questions concerning scam involvement, type of scams and the emotional and psychological impacts on the victim. Participants included the following: $n=9$ older scam victims, $n=2$ carers of older people, $n=1$ scam victim under 65 . Participants had been involved in a range scams including $n=1$ rogue trader, $n=2$ fake investment, $n=1$ responding to a scam email from the bank, $n=7$ 'luxury' goods catalogue scams, $n=3$ clairvoyant scams, $n=7$ lottery scams. $n=9$ had been involved in multiple types of scams. The aim was to gain insight into the experience of financial scams on older people, including how and why the individual first became involved with the scam, the frequency of contact, and the impact on their lives and relationships, both materially and psychologically/emotionally. A purposive qualitative sampling strategy (Patton, 1990), using contacts generated by the National Trading Standards Scams Team was used. Ethical approval was gained through the Bournemouth University Ethics Committee.

Analysis used a narrative approach which focused on the individual's experience of scams (Andrews et al., 2013). Interviews were transcribed verbatim and read multiple times enabling insights into scams and involvement in scams to emerge. These insights were grouped into related themes, and those related to the key factors identified in the literature search are discussed in the following results section. To protect the anonymity of the participants pseudonyms are used. 


\section{Results}

Participants revealed a number of vulnerability factors which appeared to make them susceptible to responding to a scam. These include the following three themes.

\section{Loneliness and social isolation}

Loneliness was identified by many of the participants as a significant factor leading them, or their relative, to respond and then maintain involvement in scams. Their loneliness or social isolation was triggered by a range of life events, including bereavement, divorce, living away from family and friends and prolonged illness. For some, loneliness was transitory related to particular events, but this feeling passed with time as they readjusted to their altered circumstance.

Bill lost his wife after nearly 50 years of marriage and found comfort in receiving extensive amounts of post (10-12 scam items daily), which he would spend time sorting and replying to:

Bill: With my wife passing away I missed her terrible (sic) and this thing that was coming through the post was like a, I don't know, every morning l'd be there waiting for the post to come. I wasn't interested in what it was, it was just something coming in to the house, because the house was so empty. It was like opening a door to people coming in, and I got invited in, and it was like opening and reading and listening to people talking.

However, Bill found that his reliance on his contact with scammers reduced over time as he regained confidence and recovered from his bereavement:

Bill: It was a difficult time but yeah, l'm over it now.

The transitory nature of Bill's scam involvement demonstrates the dynamic of vulnerability which is not a fixed state but results from the impact of diverse factors. In Bill's case these factors were his low mood and loneliness following his wife's death. He sought a source of frequent social contact, delivered to his home to make it feel like a welcoming place again.

Margo also identifies how bereavement and subsequent period of loneliness made her more susceptible to scam involvement.

Margo: I was vulnerable, I was lonely, I was lost, I had a few pounds.

For Jean the impact of dealing with prolonged illness, when she could not leave her home for many months, resulted in her low mood and sense of isolation. She found comfort in the 
reliable and frequent mail contact with scammers. She especially looked forward to receiving packages of 'luxury' goods and loyalty 'rewards'.

Jean: It was like Christmas every day and gave me a boost.

Like Bill and Margo, as her personal situation slowly resolved and the factors which created her vulnerability changed, Jean found that she no longer required the comfort and pleasure derived from the scam mail contact. In these cases professional intervention occurred at a time when the individual was ready to accept advice.

However, for other participants their loneliness and isolation was more enduring and impacted on their readiness to accept intervention to stop their contact with scammers:

Sam (carer): They all (professionals including her GP, bank, trading standards, police and social worker) get the same 'I do not want your help; I know what I am doing'. She says it to everybody. She will not listen, she just doesn't absorb or she's not prepared to absorb or listen to anybody.

A key aspect of loneliness and social isolation identified by some participants was the absence of trusted people to consult. They linked the absence of someone with whom they could discuss the proposed financial transaction to increased scam involvement, because the opinion of a trusted other would have supported them to make an informed decision.

Margo: Never having dealt with that sort of thing before and not having any family or anything to advise me, I thought well okay, and did it.

Lucy: I don't know any of these things. I don't know how much they can charge, l've got no one to ask.

\section{Rationalising on-going scam involvement}

Mental capacity was not an issue within this sample because the all participants had capacity; however, the two carers interviewed had relatives who lacked capacity. Although mental capacity is not explored in any depth in this paper, other factors linked to financial capability and well-being proved significant. This is discussed in relation to how victims rationalise their on-going involvement in scams, and their overestimation of their own financial literacy and decision-making skills. Another key factor influencing financial decision making was the plausibility or genuine appearance of the scam approach. 
The majority of participants described themselves or their relative as financially aware, although the carers stated that this awareness was no longer the case as dementia had affected their relative's financial skills, for example:

Sam: She was always in charge of the finances throughout their marriage and she was incredibly strict and disciplined with money, she was very, very financially astute.

Participants used phrases such as 'unscammable' (Margo), 'ok with money' (Lucy), 'never been in debt' (Eve), 'run multi-million-pound business' (John), 'I don't owe anybody anything, I manage fine' (Bill), to demonstrate their financial literacy.

Some rationalised their ongoing involvement by framing it as a way of catching the scammers directly themselves, explaining that maintaining their involvement is necessary in order to catch the scammers:

Eve: Everybody says you should throw everything away. Now if you start throwing things you've got nothing to prove where they're going or where they've been. You can't keep track of them. If they are writing to you, you've got a hold on them. You can keep track of them, you can catch them. And if you put pressure on them, you can make them make a mistake.

Eve reflects that her determination to tackle scammers is due to her wartime and professional experiences; however her narrative demonstrates continued involvement in scam activity which she describes as authentic:

Eve: Well, I do the ones (lotteries) that are government qualified, that the government say are genuine. They have a red tick on the back of the envelope. They also tell you to be aware of scams.

John also credits his determination to confront scammers to his wartime role in army intelligence:

John: I got the information then; I will do it again now and catch them out.

Both of these accounts demonstrate that even with the best intentions of tackling scammers, they continue to be caught in notions of the plausibility of scams.

Scammers' use of technology and marketing techniques can make distinguishing between scams and genuine opportunities difficult to judge in terms of their presentation alone. All the participants became involved in scam schemes because they thought the opportunity or service was genuine, finding the information they read or heard credible.

Bill: It was the way that it was written, like he knew me. 
Margo: The chap who spoke on the video guaranteed you would never lose any money, that if your investments went down he would cover the money, so you felt very secure. He called me and we spoke long and hard...I thought I was dealing with a good guy.

Lucy: I went online, looked up the first advert, said no call-out fee, local and sounded all very good so I called them.

Jean: well I got the items I ordered, but not the prize I thought was coming

Eve: I definitely won the grand prix prize

Dave: I mean one of them (clairvoyant) I thought was very good, and I thought she was the lady, and I thought this will be fine. It was the way it was laid out, she discovered I am a Scorpion and that put her on the right track.

\section{Psychological and emotional factors}

Responding and maintaining involvement in scams involves complex psychological and emotional processes related to the individual's needs and visceral urges. The motivation of some victims to participate in scams was a desire to meet the needs of loved ones. For others satisfying their own desires was the focus.

Eve: My sister - who's in Canada, who's ninety-six - at the moment has to have 24 hour care which is very expensive over there. And that money would have come in handy to pay for her care. So that's what started me off.

Sam: It kind of began really with her trying to help out my sister who was having a rough time, it was to try to win a bit of money.

Jim: I saw those letters and I thought 'Ooh l've got the chance to go abroad' as I've wanted to go to Canada for years.

Two accounts used the simile of addiction to describe their experience of scams and motivation driven by a compulsive urge.

Bill: I couldn't close the door, I thought it might be right and I might be a winner. I thought oh that looks appetising. It's like a drug, you start drinking half a pint and then you have a pint, then you have a pint and a half, the next thing you know you are drinking a bottle of whiskey and that is how this was, it rolled like stone and the rolling stone didn't want to stop.

Kay (carer): She knew he was doing wrong but she got addicted. It's almost like a drug addict, you know it's not good for your health, but they're still doing it.

Others described similar behaviours but did not associate this with the simile of addiction. 
Jean: I just wanted the boost of having something arrive every day to unwrap and look forward to.

Dave: It looked so good, appetising, and I think oh a present for Lyn (partner) and it makes you feel nice.

The techniques used by scammers to create high emotional arousal are illustrated by Lucy's account:

Lucy: he kept pushing 'cause he said: 'you're already paying and time is ticking, the clock is ticking you need to make a decision now' so I said 'Okay you have to use the chemicals. Still didn't expect over £1000. That was a shock.'

Some of the participants describe the use of emotional manipulation by scammers to draw in victims and sustain the abuse. These techniques are associated with the grooming of victims of sexual exploitation, including building emotional bonds, building bonds of joint interest and enforcing secrecy (Bennett and O'Donohue, 2014).

Margo: They groomed me daily building a relationship over the phone 'cause they didn't have to do anything. It was almost as though I was their mum 'Oh, you're just like my mum, I wish you were my mum you're so lovely, you're so kind, you're so generous, I love you.'. He said he was coming to London and would come and see me, he was looking at maps. They found out I don't have a family that I was on my own, that I'd lost my hubby....and I was so glad of a phone call, happy to have that contact.

Bill: Once you're on the end of the hook it's like a fish, and they reel you in.

Sam: It is still ongoing and over a period of 8 years my mother has been completely secretive...she was told not to tell anyone.

Trust is an important factor in the participants' accounts. Firstly, trust in the ability of consumer protection legislation and systems to protect individuals' interests; secondly, trust in the integrity of individuals, businesses and advertisements; and thirdly, trust in their own ability to discern genuine opportunities or services. Proof that their trust was misplaced in the latter two areas had profound effects on respondent's well-being.

Margo: Emotionally it's the trust level, it's zero now, I trust no one. Why did it have to happen to me? I start to get angry with myself and that's when the doubt comes in and you start to question everything. Nobody knows what has happened to me because I am so embarrassed through feeling stupid. 
Lucy: It definitely ruins your self-confidence. Wherever I go I just feel like everyone is laughing at me.

\section{Discussion}

The interviews illustrate how involvement in scams is a complex phenomenon, mediated by psycho-social factors and the methods of lures and entrapments used by scammers. The findings indicate that many people are overconfident in their skills of financial literacy and ability to spot a scam. One way of reducing risk of scam involvement is to equip older people with increased knowledge and understanding of the risks posed by scams so that they are better able to protect themselves. The use of educational games as learning tools has the ability to teach and reinforce not only knowledge but also skills (Dicheva et al. 2015). Learning tools in the form of games have been found to support the acquisition of better financial decision-making (Koivisto \& Hamari, 2014), and another potential approach concerns forewarning those at risk individuals to reduce their susceptibility to future scams (Scheibe et al. 2014).

The findings also reveal the significance of psychological and emotional factors in scam engagement (Sprenge et al., 2017). This includes how individuals are groomed into trusting relationships with scammers, and how ultimately the discovery of a scam undermines selfconfidence and trust in others (Olivier et al., 2015). The findings illustrate the role of high emotional arousal in the presentation of scams which are designed to elicit emotional responses in the victims, for example offering a time limited opportunity of a lifetime (Fischer, Lea and Evans, 2013).

It is important for social work professionals to be scam aware and for agencies to have protocols and procedures in place, for example, when older individuals make unusual or large bank transfers or withdrawals (Lichtenberg, 2016; Financial Fraud Action, 2017). As professional knowledge and understanding of the risks posed by financial exploitation of older people increases, new tools which support understanding of the complexities of financial decision making may aid professional understanding of individual vulnerability. For example, these include the Older Adult Financial Exploitation Measure (Conrad et al. 2010), and the Lichtenberg Financial Decision Screening Scale (LFDSS) which provide tools for assessing financial decision making and preventing financial exploitation. Although such tools need rigorous testing, they may be a further means of supporting professionals who 
seek to disrupt financial scammers whilst supporting those who fall prey to them (Lichtenberg, Ficker et al. 2016).

In England, The Care Act, 2014, specifically cites scams as a form of financial abuse (s42 (3)) and requires social workers and other professionals with safeguarding responsibilities to seek ways of preventing and protecting adults at risk. The recently updated Care Act Guidance $(2017$, s14) elaborates on types of scams to enable practitioners to recognise and respond appropriately. Practitioners' need to develop person centred approaches in line with Making Safeguarding Personal policy to recognise the wider psycho-social elements involved in scam involvement. For example, recognising that loneliness may undermine wellbeing and increase scam susceptibility, whilst working to combat loneliness through a community assets approach to combating financial scams (Nicholl, 2014). It is important to recognise the wider impacts on well-being of scam involvement including depression and anxiety, increased social isolation and loss of confidence to continue to live independently (Lee and Baxter, 2017).

This study has methodological limitations linked to sample size $(n=12)$, the exclusion of those who lack mental capacity, and the recruitment of participants via Trading Standards Scams Team. Insights revealed in this exploratory study highlight the need for further research into the factors which increase scam susceptibility. It is clear from the literature review and interview data that when vulnerability factors intersect with apparent ways of meeting needs such as loneliness, some individuals become increasingly at risk of scam involvement. Future research is required with a larger sample, including those who lack capacity, and who may not currently be known to Trading Standards. This will help to broaden understanding of vulnerability factors linked to scam involvement, and contribute to the knowledge base for professionals charged with supporting those who respond to financial scams.

\section{Conclusion}

This paper has highlighted the growing risk to older people from financial scams and the negative impact on health and well-being. In England, the Care Act, 2014, provides a framework for practitioners to intervene in cases of financial abuse whilst supporting the well-being of adults at risk of abuse. However, the risks posed by financial scams are on a global scale affecting older people in communities across the world. This requires collaboration and integrated solutions as scams have no borders. Social workers have an 
important role to play in joined up responses with other key agencies, such as the police and trading standards, as they have privileged access to people at risk and at points of crisis.

\section{References}

Adult Social Care statistics, NHS Digital (2016) Safeguarding Adults Annual Report, England 2015-16 Experimental Statistics. Health and Social Care Information Centre Available at: https://www.gov.uk/government/uploads/system/uploads/attachment data/file/557866/SAC 1516 report.pdf

Alzheimer's Society (2011) Short changed: Protecting people with dementia from financial abuse. Available from: http://alzheimers.org.uk/site/scripts/download info.php?filelD=1296

Andrews, M., Squire, C. and Tamboukou, M. (2013) Doing Narrative Research. London: Sage.

Arms, S. (2010) Romance Scam: Scammers Feign Affection to Commit Fraud. Available from http://crime.suite101.com/article.cfm/romance scam

Barratt, M (2012) Operation Liberal: Doorstep Crime Prevention 2012 Good Practice Guide. Ripley: Derbyshire Constabulary, Design and Print Section.

Bennett, N. and O'Donohue, W. (2014) The Construct of Grooming in Child Sexual Abuse: Conceptual and Measurement Issues. Journal of Child Sexual Abuse, 23:957-976, doi: 10.1080/10538712.2014.96063

Budd, C. and Anderson, J. (2009) Consumer fraud in Australasia: Results of the Australasian consumer fraud taskforce online Australia surveys 2008 and 2009. Technical and Background Paper, 43. Available from https://www.publicsafety.gc.ca/lbrr/archives/cnmcs-pleng/cn31047026-eng.pdf

Burnes, D. Henderson Jr, C.R. Sheppard, C. Zhao,R. Pillemer, K. and Lachs, M.S. (2017) Prevalence of Financial Fraud and Scams Among Older Adults in the United States: A Systematic Review and Meta-Analysis, American Journal of Public Health, 107 (8), pp.1321. 
Button, M., Lewis,C., \& Tapley, J. (2009). Fraud typologies and victims of fraud: Literature review. London: National Fraud Authority.

Carcach C. Graycar A. and Muscat G. (2001). The Victimisation of Older Australians. Barton, ACT: Australian Institute of Criminology, 1-6.

Care Act 2014, c. 23 (2014). London: The Stationery Office.

Carstensen, L. L., Mikels, J. A. and Mather, M. (2006) Aging and the intersection of cognition, motivation, and emotion. In J. Birren \& K. W. Schaie (Eds.), Handbook of the Psychology of Aging, pp. 343-362.

Choi, N, G, Kulick, D, B and Mayer, J (1999) Financial exploitation of elders: Analysis of risk factors based on county adult protective services data, Journal of Elder Abuse \& Neglect, 10(3/4), pp. 39-62.

Clarke, C.L. (2009) Risk and long-term conditions: the contradictions of self in society. Health, Risk \& Society, 11 (4), pp. 297-302.

Conrad, K.J., Iris, M., Ridings, J.W., Langley, K. and Wilber, K.H., (2010) Self-report measure of financial exploitation of older adults. The Gerontologist, 50(6), pp.758-773.

Cross, C. (2016) 'They're very lonely': Understanding the fraud victimisation of seniors. International Journal for Crime, Justice and Social Democracy, 5(4), pp. 60-75.

Cross, C. (2017) 'But l've never sent them any personal details apart from my driver's licence number...': Exploring seniors' attitudes towards identity crime, Security Journal, 30(1), pp.74-88.

Day, T. (2017) Doorstep crime: rogue trading and distraction burglary, In L. Fenge, S. Lee and K. Brown (Eds) (2017) Safeguarding Adults: Scamming and Mental Capacity, London: Sage Learning Matters

Department of Health (2014) The Care Act, London: HMSO 
Department of Health. (2017). Care and Support Statutory Guidance Issued under the Care Act 2014 (updated August 2017). London: The Stationery Office. Available from:

http://www.gov.uk/guidance/care-and-support-statutory-guidance.

Dicheva, D. Dichev, C. Agre, G. and Angelova, G. (2015) Gamification in education: a systematic mapping study, Journal of Educational Technology \& Society, 18(3), p.75-88.

Europol (2011) OC-scan threat notice 009-2011. Available from:

https://www.europol.europa.eu/sites/default/.../oc-scan-policy-brief-open-version.pdf

Financial Fraud Action (2014) New Figures Show Steep Rise in Telephone Scams, [Online] Available at:

http://www.financialfraudaction.org.uk/cms/assets/1/phone\%20scams\%20press\%20release \%20-\%20embargoed\%20until\%202\%20dec\%202014\%20-\%20final.pdf

Financial Fraud Action (2017) Advice. Available at:

https://www.financialfraudaction.org.uk/consumer/advice/

Fischer, P. Lea, S. and Evans, K. (2013) Why do individuals respond to fraudulent scam communications and lose money? The psychological determinants of scam, Journal of Applied Social Psychology, 43 (10), pp. 2060-2072.

Gamble, K.J. Boyle, P. Yu, L. and Bennett, D. (2014) The causes and consequences of financial fraud among older Americans. CRR WP 2014-13 Center for Retirement Research at Boston College, Available from https://pdfs.semanticscholar.org/7f81/d7074743275d9f4c1e7a10a3bad9c77421ab.pdf

Gibson, S. and Qualls, S. (2012) A Family Systems Perspective of Elder Financial Abuse, Journal of the American Society on Aging, 36 (3), pp.26-29.

Han, S.D. Boyle, P.A. James, B.D. Yu, L. and Bennett, D.A. (2016) Mild cognitive impairment and susceptibility to scams in old age, Journal of Alzheimer's Disease, 49(3), pp.845-851.

Holtfreter, K., Reisig, M.D. and Blomberg, T.G. (2006) Consumer Fraud Victimization in Florida: An Empirical Study. St Thomas Law Review, 18(3), pp.761-789. 
Holtfreter, K. Reisig, M. D. Mears, D. P. and Wolfe, S. E. (2014) Financial exploitation of the elderly in a consumer context, Available from https://www.ncirs.gov/pdffiles1/nij/grants/245388.pdf

Hsu, J.W. and Willis, R. (2013) Dementia risk and financial decision making by older households: The impact of information, Dementia, 7(4),45. Available from: https://dx.doi.org/10.2139\%2Fssrn.2339225

Judges, R.A. Gallant, S.N. Yang, L. and Lee, K. (2017) The Role of Cognition, Personality, and Trust in Fraud Victimization in Older Adults, Frontiers in Psychology, 8.

doi: https://dx.doi.org/10.3389\%2Ffpsyg.2017.00588

Kang, Y and Ridgway, N (1996) The Importance of Consumer Market Interactions as a Form of Social Support for Elderly Consumers. Journal of Public Policy \& Marketing, 15 (1), pp. 108-117.

Kircanski, K. Notthoff, N. Shadel, D. Mottola, G.R. Carstensen, L.L. and Gotlib, I.H. (2016) Heightened Emotional States Increase Susceptibility to Fraud in Older Adults. Stanford Centre of Longevity Available from https://www.researchgate.net/profile/Gary Mottola/publication/303381421 Heightened Emo tional States Increase Susceptibility to Fraud in Older Adults/links/573f2d0308ae9ace8 4133f15.pdf

Koivisto, J. and Hamari, J. (2014) Demographic differences in perceived benefits from gamification, Computers in Human Behavior, 35, pp.179-188.

Kopp, C. Layton, R. Sillitoe, J. and Gondal, I. (2015) The Role of Love stories in Romance Scams: A Qualitative Analysis of Fraudulent Profiles, International Journal of Cyber Criminology, 9(2), pp.205-217.

Langenderfer, J. and Shimp, T.A. (2001) Consumer Vulnerability to Scams, Swindles, and Fraud: A New Theory of Visceral Influences on Persuasion, Psychology and Marketing, 18, pp. 763-783.

Lea, S. E.G. and Webley, P. (2006) Money as tool, money as drug: the biological psychology of a strong incentive, Behavioural Brain Sciences, 29 (2), pp.161-209. 
Lee, J. and Geistfeld, L. (1999) Elderly consumers' receptiveness to telemarketing fraud, Journal of Public Policy and Marketing, 18(2), pp.208-217.

Lee, S. and Baxter, L. (2017) Adult safeguarding and financial abuse from scams, In L. Fenge, S. Lee and K. Brown (Eds) (2017) Safeguarding Adults: Scamming and Mental Capacity, London: Sage Learning Matters.

Li, J.C. Yu, M. Wong, G.T. and Ngan, R.M. (2016) Understanding and preventing financial fraud against older citizens in Chinese society: Results of a focus group study, International journal of offender therapy and comparative criminology, 60(13), pp.1509-1531.

Lichtenberg, P.A. (2016) The Intersection of Financial Exploitation and Financial Capacity, The American psychologist, 71(4), pp.312-320.

Lichtenberg, P.A. Sugarman, M.A. Paulson, D. Ficker, L.J. and Rahman-Filipiak, A. (2016) Psychological and functional vulnerability predicts fraud cases in older adults: Results of a longitudinal study, Clinical gerontologist, 39(1), pp.48-63.

Lichtenberg, P.A. Ficker, L. Rahman-Filipiak, A. Tatro, R. Farrell, C. Speir, J.J. Mall, S.J. Simasko, P. Collens, H.H. and Jackman Jr, MD, J.D. (2016) The Lichtenberg Financial Decision Screening Scale (LFDSS): A new tool for assessing financial decision making and preventing financial exploitation, Journal of elder abuse \& neglect, 28(3), pp.134-151.

Lubben, J. Gironda, M. Sabbath, E. Kong, J. and Johnson, C. (2015) Social Isolation Presents a Grand Challenge for Social Work, American Academy of Social Work and Social Welfare Working Paper No. 7 Available from http://aaswsw.org/wpcontent/uploads/2015/03/Social-Isolation-3.24.15.pdf

Marson, D.C. (2001) Loss of financial competency in dementia: Conceptual and empirical approaches, Aging, Neuropsychology, and Cognition, 8, pp.164-181.

Marson, D.C. Martin, R.C. Wadley, V. Griffith, H.R. Snyder, S. Goode, P.S. and Harrell, L.E. (2009) Clinical interview assessment of financial capacity in older adults with mild cognitive impairment and Alzheimer's disease, Journal of the American Geriatrics Society, 57(5), pp.806-814. 
National Council of Aging (2015) 10 Top Scams targeting seniors Available from:

https://www.ncoa.org/economic-security/money-management/scams-security/top-10-scamstargeting-seniors/

National Trading Standards Scams Team (2015) Scams Toolkit: A Holistic Guide to Mail Fraud [Online] Available at:

http://www.ageuk.org.uk/brandpartnerglobal/swanseabayvpp/documents/scams\%20toolkit e dition\%201 april\%2015.pdf

Nicholl, A (2014) Neighbourhood Approaches to Loneliness: A Briefing for Local Government, York: Joseph Rowntree Foundation.

Olivier, S. Burls, T. Fenge, L. and Brown, K. (2015) "Winning and losing": vulnerability to mass marketing fraud, The Journal of Adult Protection, 17 (6), pp.360 - 370.

Patton M.Q. (1990) Qualitative Evaluation and Research Methods, 2nd (Ed) Sage: Newbury Park, California.

Penhale, B. Chair, Lloyd-Sherlock, P. Co-Chair: and Lachs, M.S. Discussant (2017) Presidential Symposium: Comparative Perspectives on the Financial Exploitation of Older Adults, Innovation in Aging, 1 (suppl_1), pp.725-726.

Redmond, M. (2016) From "intrusive" and "excessive" to financially abusive? Charitable and religious fund-raising amongst vulnerable older people", The Journal of Adult Protection, 18 (2), pp.86- 95.

Reiboldt, W. and Vogel, R.E. (2003) A critical analysis of telemarketing fraud in a gated senior community, Journal of Elder Abuse \& Neglect, 13(4), pp.21-38.

Scheibe, S. Notthoff, N. Menkin, J. Ross, L. Shadel, D. Deevy, M. and Carstensen, L.L. (2014) Forewarning reduces fraud susceptibility in vulnerable consumers, Basic and applied social psychology, 36(3), pp.272-279.

Smith, R.G. and Budd, C. (2009) Consumer fraud in Australia: Costs, rates and awareness of the risks, Trends \& Issues in Crime and Criminal Justice (382), Canberra: Australian Institute of Criminology. 
Social Care Institute of Excellence (SCIE) (2011) Black and minority ethnic people with dementia and their access to support and services, Research Briefing 35, London: Social Care Institute for Excellence.

Spreng, R.N. Cassidy, B.N. Darboh, B.S. DuPre, E. Lockrow, A.W. Setton, R. and Turner, G.R. (2017) Financial Exploitation Is Associated With Structural and Functional Brain Differences in Healthy Older Adults, Journals of Gerontology Series A: Biomedical Sciences and Medical Sciences, Available from https://doi.org/10.1093/gerona/glx051

Stiegel LA. (2012) An overview of elder financial exploitation, Generations, 36, pp.73-80.

Theurer, K. Mortenson, W.B. Stone, R. Suto, M. Timonen, V. and Rozanova, J. (2015) The need for a social revolution in residential care, Journal of aging studies, 35, pp.201-210.

Whitty, M.T. and Buchanan, T. (2012) The online romance scam: A serious cybercrime, CyberPsychology, Behavior, and Social Networking, 15(3), pp.181-183.

Whitty, M. T. (2013) Anatomy of the online dating romance scam, Security Journal, 28(4), pp. 443-455.

Whitty, M. T. (2015) Mass-marketing fraud : a growing concern, IEEE Security \& Privacy, 13 (4), pp. 84-87. 